\title{
Interactional Feedback in Naturalistic Interaction between L2 English Learners
}

\author{
Mahishi Ranaweera ${ }^{1}$ \\ ${ }^{1}$ English Language Teaching Unit, University of Kelaniya, Sri Lanka \\ Correspondence: Mahishi Ranaweera, English Language Teaching Unit, University of Kelaniya, Sri Lanka. Tel: \\ 94-716-861-177. E-mail: mahishi@kln.ac.lk; mahishicestmoi@yahoo.com
}

$\begin{array}{lc}\text { Received: May 20, } 2015 & \text { Accepted: September 27, } 2015 \quad \text { Online Published: September 28, } 2015 \\ \text { doi:10.5539/elt.v8n11p47 } & \text { URL: http:/dx.doi.org/10.5539/elt.v8n11p47 }\end{array}$

\begin{abstract}
Theoretical and empirical data support that the feedback given in small group activities promote second language acquisition. There are many studies that have examined the impact of interaction on second language acquisition in controlled language situations. This study examines the small group activity 'conversation partner' in order to find out how much feedback takes place in an out of classroom activity such as conversation partner where the language is not controlled. The conversations were recorded and examined for instances of interactional feedback. Later a tailor made test was given to find out whether the participants remembered the language items that they received feedback on. The results show that feedback in natural speech among learners occurs relatively at a low level but the learners remember whatever language that was used in feedback instances.
\end{abstract}

Keywords: second language acquisition, interactional feedback, small group activities

\section{Introduction}

Interactional and small group activities are widely used in second language teaching contexts. It is believed that group work presents learners more opportunity to actually use the target language than teacher fronted activities (McDonough, 2004). Learners provide each other with learning opportunities during pair and group activities. Group activities lessen anxiety in using a second language and the feedback one gets from her/his peers is said to enhance acquisition. Numerous studies support these views and confirm the theories such as interaction hypothesis (Long, 1983, 1985, 1996) and output hypothesis (Swain, 1995). The Interaction Hypothesis claims that second language acquisition is enhanced by having L2 learners negotiate meaning. It is also found that input becomes comprehensible through the speech modifications between native speakers of the target language and learners (Long 1983).

McDonough (2004) examined learner- learner interaction during pair and small group activities in a Thai EFL context in order to find out whether theoretically attributed learning opportunities take place in an intact classroom. Sixteen Thai EFL learners had carried out four pair and small group activities and completed three oral tests over a period of eight weeks. Her study shows that learners who had more involvement with negative feedback and modified output during pair and small group activities demonstrated improved language production particularly in the production of both real and unreal conditionals. The implication of this study is that learners can create language opportunities during task-based interaction and benefit from these opportunities.

Dobao (2014) discusses the opportunities interaction offers for vocabulary learning. This study shows that the knowledge about language was jointly constructed by the participants in both the pair activity and group activity. Dobao looked at 60 learners working as groups of 4 and a further 50 learners working in pairs. Findings show that the groups produced more Language Related Episodes (LREs) than the pairs. Further the study shows that the number of participants in an interactive conversation has no adversary impact on vocabulary learning.

In another study John Bitchner (2004) investigated, the role of negotiation in interaction and the relationship between the negotiation of meaning and language learning. 30 pre-intermediate ESL learners had been asked to repeat two different communication tasks one week and 12 weeks after their first performance. This study confirms that low proficiency ESL learners initiate negotiation routines when they are faced with communication 
difficulties and they notice the gap between their utterances when they receive target like feedback from their conversational partners. Bitchner found that the learners would modify their utterance following the conversational partners and the instances of successful modification were an indication that learning may have occurred. This study shows that interaction with modified output promote second language learning.

In a study which actually examined how the subject-matter content assists the interactional and linguistic needs of classroom language learners, Pica (2002) shows that subject matter content provides opportunities for interaction particularly with respect to negotiation of meaning. The content-based classes observed in this study partially focused on culture. Since the participants of the small group activity that is observed in the present study come from different cultures and their conversations drew on cultural comparisons in several occasions it was felt that it is relevant and interesting to find how content or themes provide opportunities for interaction and meaning negotiation. The study suggests that although the discussions involved language to discuss the content they did not focus on L2 form to promote L2 learning. It would be interesting to see in the present study what type of meaning negotiation emerges related to cultural comparisons and whether the participants concentrate more on negotiating the bare meaning than focusing on producing more target- like utterances.

The above mentioned studies are examples of classroom based studies that basically show that when opportunities are provided for learners to interact through small group activities they use it to enhance their second language acquisition. The following three are lab based studies that look at small group activities and second language acquisition.

Mackey (1999) in her study done with 34 ESL learners in Sydney, Australia examines the relationship between different types of conversational interaction and second language acquisition. The central question of the study is whether conversational interaction facilitates second language development. The study confirms that conversational interaction does facilitate second language development. The study focuses on question formation through interaction and only the groups that had actively participated in interaction had shown development in their acquisition of question formation.

The study done by Oliver and Mackey (2003) is an empirical investigation of the role of interactional context in exchanges between teachers and learners. One of the researchers had visited five classes several times over a period of fourteen weeks. Video recordings had been made and analyzed on one randomly selected full teaching day. In summary, this study shows that although contextual variables can affect the amount and nature of feedback and the extent to which feedback leads to modified output, interactional feedback presents opportunities for L2 learning. This further says that in terms of the use of feedback, the explicit language-focused exchanges led to modified output $85 \%$ of the time.

Garcia, Mayo and Pica's (2000) study on addressing questions and concerns about English as a Foreign Language classroom as an environment that promotes input, feedback and the production of output for second language learning shows that learner-learner interaction was not significantly different from the learner- native speaker interaction. Recordings of dyads of interaction based on an information gap task, among 14 learners of English in a laboratory setting had been made in a period of approximately one month. This study has shown that the least used feature found in interaction is negotiation and the learners resorted to other interactional strategies such as completion and self-correction to achieve lexical precision and grammatical accuracy. The study reveals advanced EFL learners to be suitable resources for each other's L2 learning. This supports the rationale behind choosing advanced EFL learners as conversation leaders in the activity, 'conversation partners', which is observed in the present study.

\subsection{Summary}

The studies reviewed above demonstrate that interaction examined in various aspects does facilitate second language acquisition. My study observes the interaction between non native speakers, outside the classroom situation in the absence of a teacher. However the conversation leader is a near native proficient English speaker as evident by his high score in TOEFL examination and by the fact that he is a graduate student in the Master's in TESL program. This means that the participants are accompanied by a proficient speaker of English as a second language even if a formal teacher is not present in the group. This also means that the conversation partners can rely on the conversation leader for meaning negotiation and in the case of a breakdown in communication if the occasion arises. 


\subsection{Significance of the Study}

Studies examined above are based on research that has been done within classroom settings and the language tasks are preplanned and controlled. The examining of conversation partner is relatively innovative as this is an observation of learning in a natural setting. Further it is claimed that learner autonomy plays a key role in second language acquisition (Little, 1999). Therefore, the findings of the current study would either support or reflect on such claims as it observes learner-learner interaction in a natural setting without teacher observation.

This research would be an empirical contribution to strengthen the research done on learner- learner interaction outside the teacher controlled settings.

The current study hopes to examine the conversation partner activity in the light of interaction hypothesis. This study would lead to assumptions that conversation partner activity to be facilitating second language acquisition and that the learners who actively participate will benefit from the activity. The following research questions were addressed: 1. Do learners provide each other with interactional feedback during conversation partner meetings? 2. Do learners remember the linguistic information targeted in the interactional feedback?

\section{Method}

\subsection{Participants}

The participants were 4 international students enrolled in the Program in Intensive English ( 2 females and 1 male) and 1 male international student enrolled in the MA TESOL program at a North American university. Particpants ranged in age from 18 to 35 and were of mixed L1 background. The participants are given the pseudonyms Romy, Yoshi, Ishtaque, and Mushtaq. Romy is from Spain, Yoshi is from Japan, Ishtaque is from Saudi Arabia and Mushtaque is from Yeman. The four participants have been in the United Stated for varying periods of time. 'Romy' has been in the US for six months, 'Yoshi' has been in the US for 7 months and 'Ishtaq' has been in the US for 2 months. All three participants had started learning English when they were 12 years old in a formal classroom context. They have no exposure to any learning of a second language other than English.

Out of the our participants one (pseudonym 'Mushtaq') was assiged the role of conversation leader by the director of the PIE program as he was an MA TESOL student with a native like poficiency level. He had a high level English language proficiency score in the TOEFL exam which was a requirement for the MA TESOL program.

\subsection{Design}

This quasi-experimental study involved a within group analysis of interaction among one group of conversation partners over a three week period. Their instances of meaning negoiation, recast, explicit correction and modified output in response to interactionl feedback was examined for the occurance of interactional feedback. Tailormade post tests were adopted to determine if learners retained the linguistic forms targeted during their interaction.

\subsection{Materials}

In addition to the audio recordings, the following instruments were used to measure learning outcomes, gather supporting data and as assessment techniques of the converstions.

\subsubsection{Tailor - Made Post Test:}

The test content was based on the episodes of interactional feedback and modified output that took place the previous week. The test contained open ended, multiple choice and scalar response items. The tests were different for each partner depending on who participated in the conversation partner activity that particular week and the feedback each partner got individually. A common test was given for all three partners based on the conversations that all three took part. See Appendix A for sample tests.

\subsubsection{Questionnaire}

In order to gain background information about the conversation partners, a questionnaire about them and the years of previous English study and exposure to learning of any other language was created and distributed among the conversation partners. See Appendix B for a copy of the questionnaire.

\subsection{Procedure}

Conversations that take place between one group of conversation partners of the Program in Intensive English at 
university were recorded over a period of three weeks. These recordings were done by the conversation leader of this group under the instructions of the researcher. A week before the recordings were made, the researcher visited the conversation group as a mere observer in one session to gain familiarity with both the conversation leader and the conversation partners.

After every conversation partner meeting the researcher listened to the tapes. Based on the instances that believed to offer an opportunity for learning, a simple test containing 3- 5 questions was created and distributed to the conversation partners at the beginning of the next conversation partner meeting by the conversation leader. The conversation partners were given 5 minutes to complete the test. There was one instance when two participants had requested that they do the review tests at home and the conversation leader had granted the request.

\section{Analysisv}

There was a recording of one hour for the first week, 1 and half hours for the second week, and a forty five minute recording for the third week. All together three and a quarter hour recording was analyzed. Certain context types were identified as opportunities for learning within the conversations between conversation partners. The clear cut instances where these opportunities occur were transcribed. These context types were classified as having a three part exchange. The three parts are a conversation partner's or conversation leader's initial utterance, the conversation leader's or a second conversation partner's response to the first conversation partner's utterance and first conversation partner's reply to that response.

\subsection{Interactional data}

Types of interactional feedback were classified into three sections: meaning negotiation, recast, explicit correction.

The following are the descriptions of coding categories adopted from studies by McDonough (2004), Oliver \& Mackey (2003) and Foster (1998). Examples are from the current study.

Negotiation of Meaning: Negotiation of meaning was operationalized as clarification requests and confirmation checks.

1) Clarification requests: A request for further information from an interlocutor about a previous utterance

2) Comprehension checks: The speaker's query of the interlocutor(s) as to whether or not they have understood the speaker's previous utterance.

(Definitions from Chaudron, 1985, as cited in Foster, 1998)

Example 1: Mushtaq: When did you come here?

Romi: mmh? When?

Mushaq: Yeah, how long have you been here?

Romi: Last August.

Example 2: Romi: What's the difference between..in the countries and..?

Mushtaq: You mean in Arabic? The language or what?

Recast: A recast was defined as a more target- like reformulation of an interlocutor's previously Non Target Like (NTL) utterance. Both partial and complete reformulations of the interlocutor's utterances were included. (McDonough, 2004)

Example: Romi: There are many program like this but 'heerachy'..(spelling used to represent pronunciation)

Mushtaq: Hierarchy?

Romi: Hierarchy.

Explicit correction: An explicit correction was defined as a response to a non-target-like utterance that indicated explicitly that the utterance was incorrect.

Explicit corrections (a) with or without a metalinguistic explanation and (b) in English or shared L1 were included (McDonough, 2004). Shared L1 refers to two or more participants sharing the same L1. For example in this study two of the participants share Arabic as their L1. 
In addition, the interaction data was analyzed in terms of modified output, which was defined as a response to interactional feedback in which a learner reformulates her previous utterance, resulting in a more accurate or complex form. (McDonough, 2004)

Example: L1: if they stopped

\section{L3: turned off}

L1: if they turned off yeah (McDonough, 2004)

First, instances in which meaning negotiation, recast and explicit correction were identified. Then the same data were further examined to find out the how the earlier mentioned criteria occurred in the linguistic areas of grammar, vocabulary and pronunciation. Thirdly, response to interactional feedback was analyzed. In response to feedback, the utterances that were modified from NTL (Non Target Like) utterances to TL (Target Like) utterances were selected as instances that provide learning opportunities.

An independent intercoder coded a subset of (50\%) for the coding categories and intercoder reliability was calculated using simple percentage agreement. Agreements for all three sections i.e. a) type of interactional feedback b) linguistic target c) response to interactional feedback was $100 \%$.

\subsection{Test Data}

The answers of each participant were corrected and tabulated in combination to examine the percentage of language that they had remembered from the language instances which marked meaning negotiation, recasts, explicit correction and modified output as interactional feedback. 1 point was given for correct answers. Half a point was given for a change that was made in recognizing a grammar slip in a grammatically incorrect sentence even if the change that was made was not correct. Completely incorrect answers were not awarded any points.

\section{Results}

The data consisted of the audio recordings of three conversation partner meetings. The average interaction time between conversation partner and leader was 1 hour and 5 minutes.

Table 1. Frequency of interactional feature

\begin{tabular}{ll}
\hline Interactional feature & No. of occurrences \\
\hline Meaning negotiation & 5 \\
Recast & 3 \\
Explicit correction & 0 \\
Modified output & 1 \\
\hline
\end{tabular}

Out of the meaning negotiation occurrences two were clarification requests and three were comprehension checks. Looking at the data it is very clear that most frequent form of interactional feature is meaning negotiation $(55 \%)$. There were no explicit corrections. The test performances were examined to see how much language the learners retain. Test 1 was given to all the participants.

Table 2. Test scores

\begin{tabular}{lll}
\hline Name of participant & Test 1 & Individual tests \\
\hline Romy & $2 / 3$ & $1 / 3$ \\
Yoshi & $3 / 3$ & - \\
Ishtaque & $3 / 3$ & $3 / 4$ \\
\hline
\end{tabular}

\section{Discussion}

One of the research questions of this study was whether the learners provide each other with interactional feedback during conversation partner meetings. The study showed positive results confirming the presence of 
interactional feedback. The post conversation test scores showed that the learners do remember the linguistic information targeted in the interactional feedback.

To summarize the findings only 08 instances of interactional feedback and just one instance of response to feedback occurred for the total three and half hours of interaction. This can be interpreted as a very low number of occurrences. In this natural interaction, similar to the study by Pica (2002) in which most of the non target utterances had gone unaddressed in any direct way, it seems that the conversation partners were more interested in communicating ideas rather than speaking grammatically correct English. There were more than twenty five instances where the learner did not use the correct target language form. However, these instances did not create a breakdown in communication. It was noticed that the conversation partners were interested in making their pronunciation more target like than paying attention to form.

Similar to Garcia Mayo and Pica (2000) study, sentence completion was used as a means of meaning negotiation between the conversation leader and conversation partner rather than between two conversation partners.

In the linguistic target questions Yoshi and Ishaque scored $100 \%$ on the common test given to all while Romi scored 66\%. In the individual tests Romi scored 33\% and Ishtaque scored 75\%. Yoshi was not given an individual test as the tapes have only one instance of her asking for meaning negotiation, specifically wanting to know to what $\mathrm{PhD}$ refers. The fact that she did not need a noticeable amount of meaning negotiation could probably suggest that she is more proficient than the other two participants. This is also supported in the high score she obtained in the common test.

\subsection{Limitations of the study}

The conversations seemed to focus on more talkative and forward students and therefore it was difficult to examine interactional features of all conversation participants in an equal manner.

As there were guests or new members who joined just for one session with the conversation group it was very difficult to focus on the conversation partners under observation in the recording. The data show that these 'visiting members' of conversation partner activity always dominated the conversation not allowing the conversation partners enough time for interaction and feedback.

In just one instance the post-conversation test was done at home by two participants. Whether the participants had help in completing the tests is unknown. There should have been better controls in place in conducting the post conversation tests.

Since conversation partner is an outdoor activity, the recording was done while the conversation partners were on the move or in public places. Therefore at times the recording was not very clear or was filled with background noise.

The number of participants too is a limitation as a larger number would have given more robust findings.

\section{Conclusion}

This study was motivated by the interest in finding whether learners provide each other with learning opportunities in the absence of supervision by a teacher. The researcher was also interested in observing second language learning in an ESL language setting where the participants do not share an L1. Considering the many studies done on the positive aspects of small group activities as a means of enhancing second language acquisition it was intriguing to pose the research questions of the current study.

The results reveled that there is only a very low number of feedback occurrences that take place in a natural conversation among learners. The results also revealed that the participants remember the language on which they got some kind of feedback. It indicates that feedback has provided the conversation partners learning opportunities.

In sum, the present study indicates that the company of an advanced ESL learner is a suitable resource for L2 learning for the other learners. This would be relieving information to ESL teachers trapped in overcrowded classrooms which is a very common situation in many parts of world. The teacher can rely on learners themselves to give opportunities to each other to enhance second language acquisition.

\section{Acknowledgments}

I wish to thank Prof. Kim McDonough, for her guidance given in conducting this research and Dr. Mansoor AlSurmi, former colleague, for assisting me in collecting the data. 


\section{References}

Bitchener, J. (2004). The relationship between the negotiation of meaning and language learning: A longitudinal study. Language Awareness, 13, 81-95. http://dx.doi.org/10.1080/09658410408667088

Dobao, A. F. (2014). Vocabulary learning in collaborative tasks: A comparison of pair and small group work. Language Teaching Research, 18, 497-520. http://dx.doi.org/10.1177/1362168813519730

Foster, P. (1998). A classroom perspective on the negotiation of meaning. Applied Linguistics, 19, 1-23. http://dx.doi.org/10.1093/applin/19.1.1

Garcia Mayo, M., Pica, M (2000). L2 learning interaction in a foreign language setting: Are learning needs addressed? International Review of Applied Linguistics in Language Teaching, 38, 35-58

Little, D. (1999). Developing learner autonomy in the foreign language classroom: A social interactive view of learning and three fundamental pedagogical principles. Revista Canaria de Estudios Ingleses, 38, 77-88

Long, M. H. (1983). Native speaker/nonnative speaker conversation and the negotiation of comprehensible input. hApplied Linguistics, 4, 126-141. http://dx.doi.org/10.1093/applin/4.2.126

Long, M. H. (1985). Input and second language acquisition theory. In S. M. Gass, and C. G. Madden (Eds.), Input in second language acquisition (pp. 377-393). Cambridge, MA: Newbury House Publishers.

Long, M. (1996). The role of the linguistic environment in second language second language acquisition in W. Ritchie and T. Bhatia (Eds.), Handbook of Second Language Acquisition (pp. 413-468).j New York: Academic Press.

Mackey, A. (1991). Input, interaction, and second language development. Studies in Second Language Acquisition, 21, 557-587

McDonough, K. (2004). Learner- learner interaction during pair and small group Convers. Leader activities in a Thai EFL context. System, 32, 207-224. http://dx.doi.org/10.1016/j.system.2004.01.003

Oliver, R., \& Mackey, A. (2003). Interactional context and feedback in child ESL classrooms. The Modern Language Journal, 87, 519-533. http://dx.doi.org/10.1111/1540-4781.00205

Pica, T. (2002). Subject-matter content: How does it assist the international and linguistic needs of classroom language learners? The Modern Language Journal, 86, 1-19. http://dx.doi.org/10.1111/1540-4781.00133 


\section{Appendix A}

Test 1. Common test to all the participants

\section{Observatory}

Choose the correct word.

a. Follow the yellow road. You can't (missed, miss) it.

Underline the correct sentence.
a. What do you saw?
b. What did you see?
c. What did you saw?

When are you going to Las Vegas?

a. On the twenty two.

b. On the twenty second.

Individual tests:Test for Romi- book store

1. Choose the correct sentence.

i) We are arrive here at the same time like with John.

ii) We arrived here at the same time with John.

2. How do you ask somebody how long he/she has been in the US? Write the question in the space below.

3. Fill in the blank with a suitable word.

It is a great.................... of art from China and now it is in the National At Gallery in London. 


\section{Appendix B}

\section{Information Sheet}

Date:

Name:

Age:

Gender:

What is your first language:

For how long have you been learning English?

Do you speak any other language as a second language other than English and if so, name it/them.

\section{Copyrights}

Copyright for this article is retained by the author(s), with first publication rights granted to the journal.

This is an open-access article distributed under the terms and conditions of the Creative Commons Attribution license (http://creativecommons.org/licenses/by/3.0/). 